\title{
TBDY-2018'deki Yerel Zemin Koşullarının Çelik Yapı Deprem Davranışına Etkisi Üzerine Bir Çalışma
}

\author{
Fatma Ülker PEKER ${ }^{1 *}$, Ercan IŞIK ${ }^{2}$ \\ ${ }^{I}$ Turgut Özal Üniversitesi, Mühendislik-Mimarlık Fakültesi, İş̧aat Mühendisliği Bölümü, Malatya \\ ${ }^{2}$ Bitlis Eren Üniversitesi, Mühendislik-Mimarlık Fakültesi, İnşaat Mühendisliği Bölümü, Bitlis \\ (ORCID: 0000-0002-0805-4367) (ORCID: 0000-0001-8057-065X)
}

\begin{abstract}
$\ddot{\mathbf{O} z}$
Depremlerin, yapılar üzerindeki etkilerini azaltmak adına yapı-zemin-deprem etkileşiminin gerçekçi olarak ortaya konulabilmesi önemlidir. Bu çalışma kapsamında, Türkiye Bina Deprem Yönetmeliğinde yer alan beş farklı yerel zemin koşulu dikkate alınarak sekiz katlı örnek bir çelik yapı için yapısal analizler gerçekleştirilmiştir. Bu güncel yönetmelik ile birlikte bölgesel bazda kullanılan tasarım spektrumları yerini sahaya özgü spektrumlara bırakmıştır. $\mathrm{Bu}$ değişimin yapısal analizlere etkisini koymak adına, 24 Ocak 2020 Sivrice (Elazığ) (Mw=6.8) depremin en çok etkilediği iki yerleşim birimi olan Sivrice (Elazığ) ve Pütürge (Malatya) için elde edilen tasarım spektrumları kullanılarak, her iki yerleşim birimi için de yerel zemin koşulları için analizler ayrı ayrı gerçekleștirilmiş̧ir. Çalışmada ayrıca iki yerleşim biriminin de içerisinde yer aldığı Doğu Anadolu Bölgesinin depremselliği ve son deprem hakkında bilgiler verilmiştir. Bu çalışma sahaya özgü tasarım spektrumlarının ve yerel zemin koşullarının çelik yapılardaki etkisini ortaya koymak adına yapılmıştır.
\end{abstract}

Anahtar kelimeler: Yerel zemin koşullar, sahaya özgü, spektrum, çelik, TBDY-2018

\section{A Study on the Effect of Local Soil Conditions in TBDY-2018 on Earthquake Behavior of Steel Structure}

\begin{abstract}
It is important to be able to demonstrate the structure-ground-earthquake interaction realistically in order to reduce the effects of earthquakes on buildings. In this study, structural analysis was performed for a sample of 8-storey steel structure by using five different local ground conditions that given in Turkish Building Earthquake Code. Site-specific earthquake spectra were started to use instead of design spectra based on regional basis with updated code. Analyses for local soil conditions were carried out separately by using the design spectra obtained for Sivrice (Elazı ğ) and Pütürge (Malatya), which are the two most affected settlements by the 24 January 2020 Sivrice $($ Elazı $\breve{g})(\mathrm{Mw}=6.8)$ earthquake, in order to show the effect of this change on the structural analysis. In the study, information about the seismicity of the Eastern Anatolia Region in which two settlements are located and the last earthquake were also given. This study was conducted to reveal the effect of site-specific design spectra and local ground conditions on steel structures.
\end{abstract}

Keywords: Local soil conditions, site-specific, spectra, steel, TBEC-2018

\section{Giriş}

Depremlerin sıkça yaşanması bu konu hakkında yapılan çalışmaların önemini artırmaktadır. Deprem tehlikesi, belirli bir bölgede ve belli bir zaman diliminde olası depremden dolayı hasar ve can kayb1 oluşturabilecek yer hareketinin meydana gelme ihtimalidir. Deprem riski, deprem nedeni ile oluşabilecek mal ve can kaybı ile hasar ihtimali olarak tanımlanabilir [1-4]. Deprem etkisindeki yapıların tasarım ve değerlendirmesinde bölgenin depremselliği, yerel zemin koşulları ve yapısal özellikler önemli faktörler olarak karşımıza çıkmaktadır. Bu faktörlerin her birinin birbirleri ile karşılıklı

"Sorumlu yazar:fatma.peker@ozal.edu.tr

Geliş Tarihi: 15.04.2021, Kabul Tarihi: 09.06.2021 
etkileşimi hem deprem ile ilgili parametreleri hem de yapısal analiz sonuçlarını etkileyecektir $[5,6]$. Son olarak meydana gelen Sivrice (Elazı $\breve{g})(\mathrm{Mw}=6.7)$ ve 2020 Ege Denizi (İzmir) $(\mathrm{Mw}=6.9)$ depremleri hem depreme dayanıklı yapı tasarım ilkeleri hem de deprem tehlike haritalarının önemini bir kez daha ortaya koymuştur.

Türkiye'de 1945, 1947, 1963, 1972 ve 1996 yenilenen deprem tehlike haritaları son olarak 2018 tarihinde güncellenmiş ve 2019 tarihinde yürürlüğe girmiştir. Son harita haricindeki tüm haritalar bölgesel risk tabanlı hazırlanmıştır. Yeni harita en güncel deprem kaynak parametreleri, deprem katalogları ve yeni nesil matematiksel modeller dikkate alınarak çok daha fazla ve ayrıntılı veriyle hazırlanmıştır. Yeni haritada, bir önceki haritadan farklı olarak deprem bölgeleri yerine en büyük yer ivmesi değerleri gösterilmiş ve "deprem bölgesi” kavramı ortadan kaldırılmıştır [7-9]. Bununla birlikte deprem tehlikesi artık coğrafi konuma özel olarak hesaplanmaya başlanmıştır [10,11]. Bu haritanın yanı sıra depreme dayanıklı yap1 yönetmeliği 2018 tarihinde güncellenmiş ve 2019 yılında yürürlüğe girmiştir. Bu yönetmelikteki önemli değişikliklerden biri yerel zemin koşullarında olmuştur. Farklı zemin grup ve sınıfları birleştirilerek yerel zemin sınıfı olarak tek bir başlık altında birleştirilmiştir.

Yerel zemin koşullarının, yapıların sismik davranışını doğrudan etkilediği bilinen bir gerçektir [12]. Tasarım spektrumu, yerel zemin koşulları ve bölgenin sismisite unsurları birleştirilerek elde edilebilir. Yerel zemin koşulları, tasarım spektrumunu önemli ölçüde etkilemektedir. Tasarım spektrumlarındaki farklılıklar yapıların hedef yer değiştirme değerlerini doğrudan etkilemektedir [1317]. Hedef yer değiştirmelerin karşılanamadığı yapılarda öngörülen performans ve hasar düzeylerinin sağlanması mümkün olamayabilir [18]. Dolayısı ile yapıların tasarım ve değerlendirilmesinin gerçekçi olabilmesi yerel zemin koşullarının ve bölgenin sismik karakteristiklerinin doğru olarak bilinmesine bağlıdır. Bu çalışma kapsamında güncel deprem yönetmeliğinde yer alan beş farklı yerel zemin sınıfı dikkate alınmıştır. Tasarım spektrumlarının yapısal analizlere etkisini ortaya koymak adına da Sivrice ve Pütürge gibi iki farklı yerleşim birimi seçilmiştir.

Doğu Anadolu Bölgesinde yer alan ve deprem riski yüksek yerleşim birimlerinden olan Sivrice ve Pütürge ilçeleri özelinde, TBDY-2018'de verilen yerel zemin koşulları dikkate alınarak örnek bir çelik yapı için farklı yüklemeler altında analizler gerçekleştirilmiştir. Çalışmada bu iki yerleşim biriminin yer aldığı Doğu Anadolu Bölgesinin depremselliği ve 2020 Sivrice (Elazığ) depremi hakkında bilgiler verilmiştir. Örnek olarak seçilen çelik yapı için farklı yüklemeler altında yapısal analizler sonlu elemanlar yöntemi kullanılarak gerçekleştirilmiştir. Her iki yerleşim birimi için tasarım depremi olarak göz önüne yer hareket düzeyi tasarım spektrumları yerel zemin koşullarının değişimine göre elde edilmiştir. Elde edilen tasarım spektrumları kullanılarak her iki yerleşim birimi için yapısal analizler ayrı ayrı gerçekleştirilmiştir. Çalışma hem yerel zemin koşullarının çelik yapıların analizlerine etkisini hem de farklı coğrafik konumlardaki etkisini ortaya koymaktadır. Sahaya özgü tasarım spektrumları ve yerel zemin sınıfları değişken olarak seçilerek elde edilen sonuçlar yorumlanmıştır. Hem yerel zemin koşullarının hem de tasarım spektrumlarının farklılaşması yapı analizlerini doğrudan etkilemektedir.

\section{Materyal ve Metot}

Çalışma kapsamında öncellikle dikkate alınan iki yerleşim biriminin yer aldığı Doğu Anadolu Bölgesinin depremselliği hakkında bilgiler verilmiştir. Bu bölümde ayrıca bu iki yerleşim birimin maruz kaldığı en güncel deprem olan 24 Ocak 2020 Sivrice_(Elazığ) $\left(M_{w}=6.8\right)$ depremi hakkında da bilgiler verilmiştir. Ayrıca güncel yönetmelik ile birlikte kullanımı zorunlu olan Türkiye Deprem Tehlike Haritaları interaktif web deprem uygulaması kullanılarak her iki yerleşim birimi için deprem parametreleri ve tasarım spektrumları elde edilmiştir.

\subsection{Doğu Anadolu Bölgesinin Depremselliği}

Doğu Anadolu Bölgesi, Türkiye'de sismik aktivitenin yoğun olarak yaşandığı bölgelerden biridir. Özellikle Bingöl iline bağlı Karlıova ilçesi, Kuzey Anadolu Fay Zonu (KAFZ) ve Doğu Anadolu Fay Zonunun (DAFZ) birleşme noktasına karşlık gelmektedir. Kıta içi transform faylar niteliğinde bu iki fayın Anadolu levhasını sınırladığı ve bunlar arasında çapraz fay sistemlerinin gelişmiş olduğu bu alan Türkiye'de diri fay uzunluğunun en fazla olduğu bölgedir (Şekil 1). Bölgenin baskın fay mekanizmaları Bitlis Kenet Kuşağı, KAFZ ve DAFZ ile ifade edilebilmektedir [19-22]. Bu bölge içerisinde yer alan, 24.01.2020 tarihinde Elazığ (Sivrice)'da meydana gelen $\mathrm{Mw}=6.8$ büyüklüğündeki deprem dikkatleri 
DAFZ üzerinde toplamıştır. DAFZ tarihsel dönem içerisinde önemli can ve mal kayıplarına neden olan depremler üretmiş Türkiye'nin ikinci önemli fay zonudur.

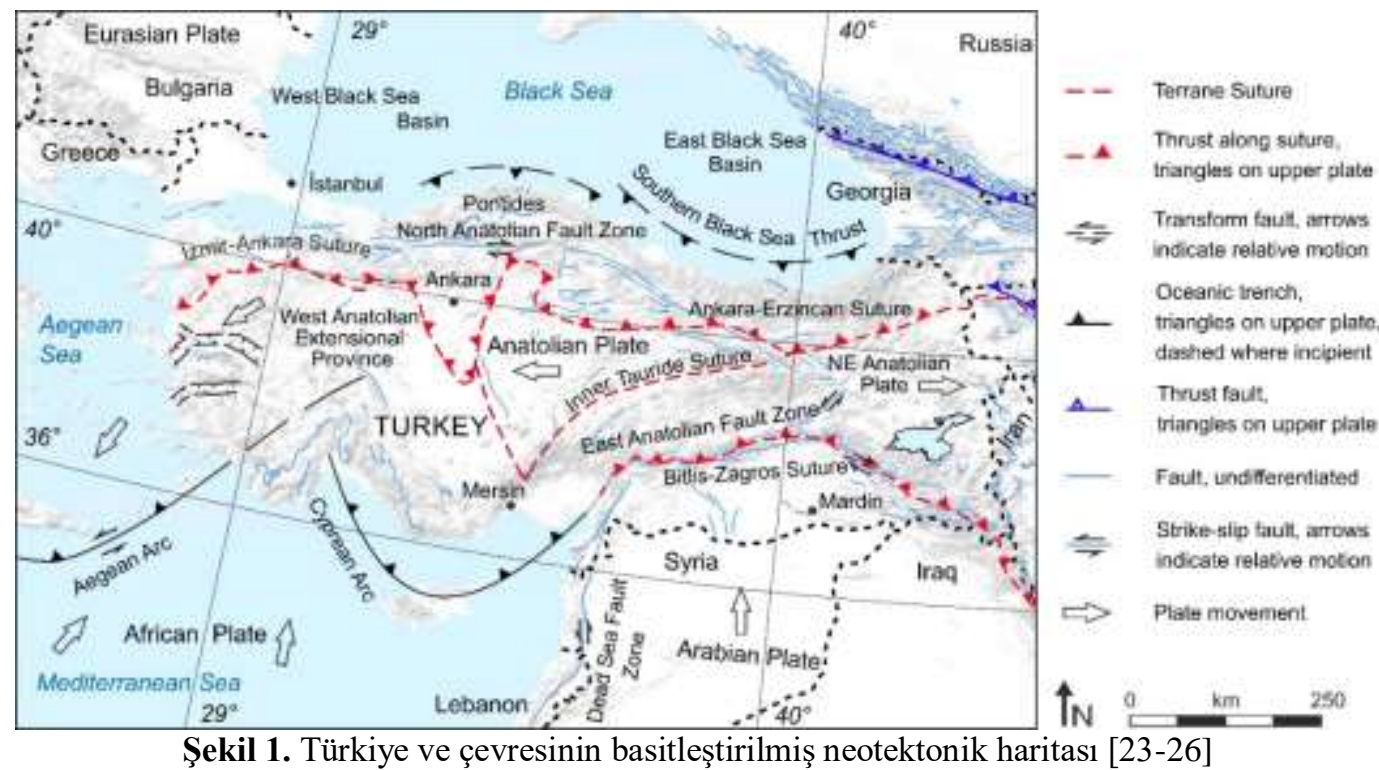

Tarihsel dönemde birçok büyük depreme kaynaklık eden DAFZ, 19. yüzyılda oldukça aktif bir dönem geçirmiştir. 1822 Antakya depremi ile başlayan 1866, 1872, 1874, 1875, 1893 depremleri ile devam eden ve son olarak 1905 Malatya depremi ile tamamlanan bir deprem serisi oluşturmuş, bu depremden sonra göreceli olarak daha sakin bir döneme girmiş, yüzey kırığı oluşturabilecek büyüklükte bir deprem üretmemiştir. Bu sessizliğin geçici olduğu ve önemli gerilmelerin biriktiği ifade edilmektedir $[21,27,28]$. Sivrice depreminden sonra dikkatleri üzerine çeken DAFZ, Arabistan plakasından Anadolu plakasını ayıran ve KAFZ'nun sol yanal eşleniği olan KD-GD doğrultulu sol yanal atımlı olup Türkoğlu civarında Ölüdeniz Fayı ile Karlıva civarında ise KAFZ ile birleşmektedir. Karlıova-Antakya arasında değişik özellikte olan birbirlerini tamamlayan birç̧ok sol yönlü doğrultu atımlı faydan oluşan zon, Doğu Anadolu Fay Sistemi olarak adlandırılmıştır [29]. DAFZ, yaklaşık $30 \mathrm{~km}$ genişliğinde, $700 \mathrm{~km}$ uzunluğundadır [30, 31]. Sivrice depremi bu sessizliği bozmuş ve yeni bir deprem serisi mi başliyor sorusunu gündeme getirmiştir. Sivrice depremi pek çok yerleşim alanında hissedilmiştir. Ana depremden sonra çok sayıda artçı depremin meydana geldiği bölgedeki can kayıpları, yaralanmalar, yapısal hasarlar ve oluşturduğu ekonomik kayıplar ile bu deprem, DAFZ deprem tarihi içindeki önemli depremler arasına girmiştir. En büyük yapısal hasarlar Elazığ ve Malatya illerine bağlı yerleşim birimlerinde oluşmuştur [32, 33]._Çalışmaya konu olan Sivrice ve Pütürge ilçelerinin içinde yer aldığ1 bölge Türkiye'nin en önemli sol yanal doğrultu atımlı aktif fay zonu olan Doğu Anadolu Fay Zonu üzerinde bulunmaktadır. İlçelerin sınırları içinden Doğu Anadolu Fay Zonu'na ait Pütürge segmenti geçmektedir. Bu faylar üzerinde yıkıcı depremler meydana gelmiştir. Özellikle Doğu Anadolu Fay Zonu ana koluna ait Pütürge segmentinin yıkıcı deprem üretebilecek sismik bir boşluk olduğu 2013 yılında belirtilmiştir [34]. Bu iki yerleşim biriminde oluşan bazı büyük depremler Tablo 1 ve Tablo 2'de verilmiştir.

Tablo 1. Elazı̆̆ ve Malatya merkezli önemli tarihsel dönem depremleri [35-38]

\begin{tabular}{|c|c|c|c|c|}
\hline Sira & Tarih & Bölge & Şiddet & Büyüklük \\
\hline \multicolumn{5}{|c|}{ Tarihsel dönem } \\
\hline 1 & 1789 & Palu (Elazığ) & VII & \\
\hline 2 & 1866 & 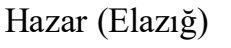 & VIII & \\
\hline 3 & 1874 & Elazığ & IX & $\mathrm{Ms}=7.1$ \\
\hline 4 & 1875 & Elazı̆g & VI & $\mathrm{Ms}=6.7$ \\
\hline 5 & 1875 & Palu (Elazı̆̆ & & $\mathrm{Ms}=6.1$ \\
\hline 6 & 1893 & Malatya & IX & \\
\hline
\end{tabular}


Tablo 2. Elazığ ve Malatya merkezli önemli aletsel dönem depremleri [35-38]

\begin{tabular}{|c|c|c|c|c|}
\hline \multicolumn{5}{|c|}{ Aletsel dönem } \\
\hline 1 & 1905 & Pütürge (Malatya) & & $\mathrm{Ms}=6.8$ \\
\hline 2 & 1964 & Malatya & VIII & $\mathrm{Ms}=6.0$ \\
\hline 3 & 1986 & Sürgü (Malatya) & VIII & $M w=6.0$ \\
\hline 4 & 2004 & Sivrice -Elazı̆̆ & VII & $M w=5.6$ \\
\hline 5 & 2007 & 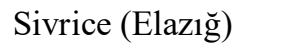 & VI & $M w=5.5$ \\
\hline 6 & 2007 & Sivrice (Elazı $\breve{g})$ & VII & $\mathrm{Mw}=5.7$ \\
\hline 7 & 2010 & Kovancılar (Elazığ) & VII & $M w=6.1$ \\
\hline 8 & 2020 & Sivrice (Elazığ) & VII & $M w=6.8$ \\
\hline
\end{tabular}

\subsection{Ocak 2020 Sivrice (Elazı̆̆) Depremi}

Konum olarak, 38.3593 enleminde 39.0630 boylamında oluşan bu depremin derinliği 8.06km olarak belirlenmiştir. Ana şoktan, 27.01.2020 12:25' e kadar geçen zamanda, büyüklükleri 0.8 ile 5.1 arasında değişen 995 artçı deprem kaydedilmiş̧ir (Şekil 2). Depremin belirgin süresi ise ilk belirlemelere göre 20.4 sn olarak hesaplanmıştır. Depremden sonra yapılan odak mekanizması çözümleri bir arada değerlendirildiğinde $\mathrm{Mw}=6.8$ büyüklüğündeki depremin sol yanal doğrultu atımlı bir fay olan Doğu Anadolu Fayının Sivrice-Pötürge segmenti üzerinde geliştiği ve yırtılmanın 50-55 km'lik bir alanda geliştiği düşünülmektedir [33]. Deprem Elazığ ili ve ilçeleri başta olmak üzere Doğu Anadolu, Güneydoğu Anadolu, Orta Anadolu ve Karadeniz bölgelerinde hissedilmiştir [39].

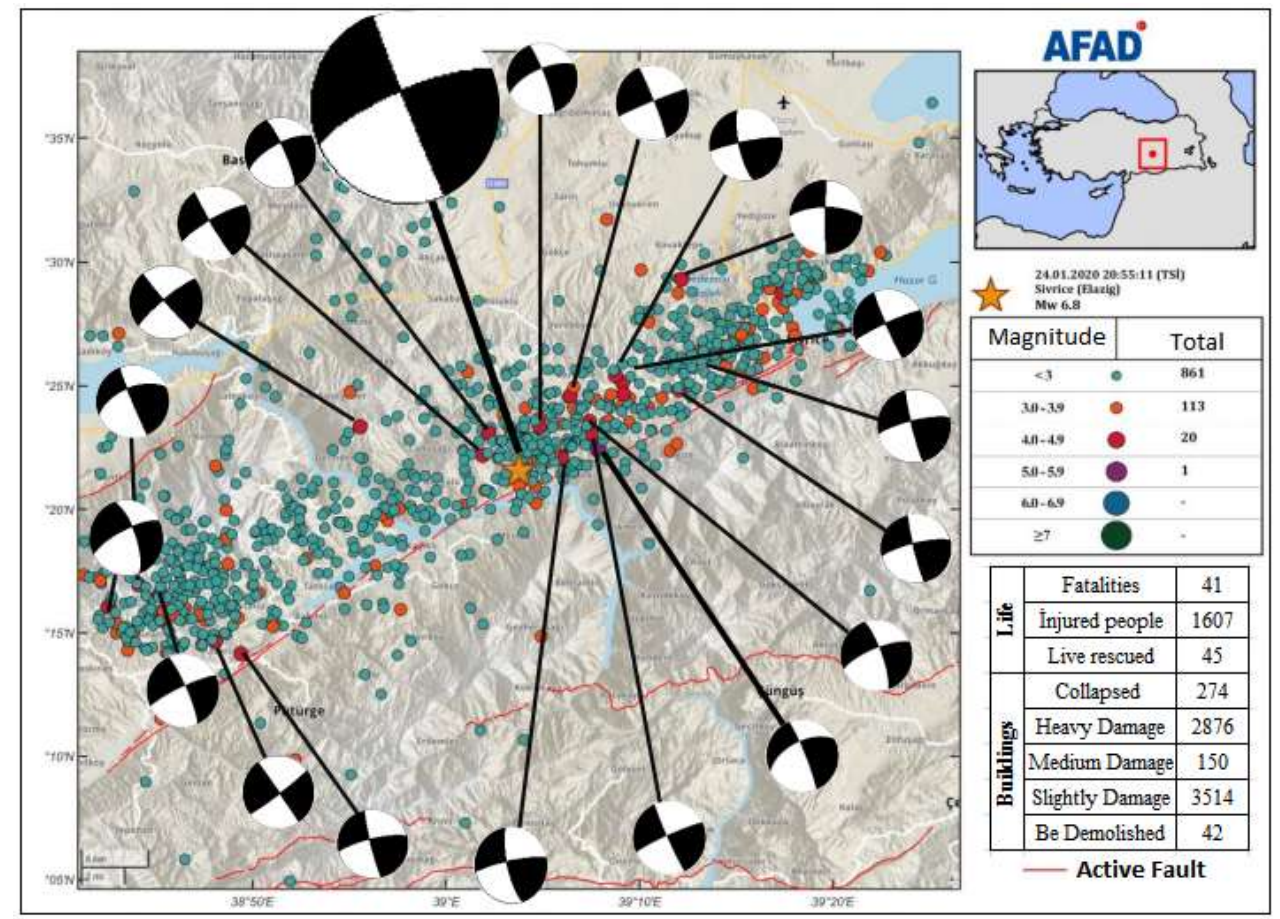

Şekil 2. Sivrice Depremi ana şok ve artçı şok aktivitesi [33]

Depremin merkez üssüne en yakın beş adet istasyondan ölçülen ivme değerleri Tablo 3'te verilmiştir.

Tablo 3. Bölgedeki ivmeölçer istasyonlar ve ölçülen ivme değerleri [33]

\begin{tabular}{ccccc}
\hline İstasyon & $\begin{array}{c}\text { K-G } \\
(\mathrm{gal})\end{array}$ & $\begin{array}{c}\text { D-B } \\
(\mathrm{gal})\end{array}$ & $\begin{array}{c}\text { Düşey } \\
(\text { gal) }\end{array}$ & $\begin{array}{c}\text { Mesafe }(\mathrm{km}) \\
\mathrm{R}_{\text {epi }}\end{array}$ \\
\hline Elazı̆̆ (Sivrice) & 237.99 & 292.77 & 190.09 & 24 \\
Malatya (Pötürge) & 206.91 & 239.24 & 153.87 & 25 \\
Adıyaman (Gerger) & 94.03 & 110.11 & 60.75 & 37 \\
Elazı̆̆ (Merkez) & 119.28 & 140.73 & 66.31 & 36 \\
Elazı̆̆ (Maden) & 26.29 & 33.97 & 22.78 & 53 \\
\hline
\end{tabular}




\subsection{Tasarım Spektrumlarının Elde Edilmesi}

Yeni deprem yönetmeliği ile geometrik konuma özel tasarım spektrumları kullanılmaya başlanmıştır. Yapıların deprem yükleri altındaki hesaplamaları için birtakım parametrelere ihtiyaç duyulmakta olup bu değerler, 2019 yılında yürürlüğe giren Türkiye Bina Deprem Yönetmeliği ile beraber oluşturulan Türkiye Deprem Tehlike Haritaları İnteraktif Web Uygulaması yardımı ile elde edilebilmektedir [40, 41]. Bu çalışma da öngörülen uygulama kullanılarak Sivrice ve Pütürge olmak üzere iki farklı coğrafik konum dikkate alınmıştır. Türkiye Deprem Tehlike Haritaları İnteraktif Web Uygulaması kullanılarak parametre değerleri farklı yer hareket düzeylerine göre hesaplanmıştır. Dikkate alınan iki coğrafik konum rastgele seçilmiş olup değerler elde edilmiştir. Dört farklı deprem yer hareket düzeyi ve beş farklı zemin sınıfı dikkate alınmıştır. Bu çalışma kapsamında seçilen her iki geometrik konum için kısa periyot harita spektral ivme katsayısı, en büyük yer ivmesi, en büyük yer hızı, yerel zemin etki katsayıları, tasarım spektral ivme katsayıları ile yatay ve düşey elastik spektrum eğrisi için hesaplamalar yapıllmıştır. İnteraktif Web Uygulamasında dikkate alınan sismik tehlike haritası Şekil 3'te gösterilmiştir

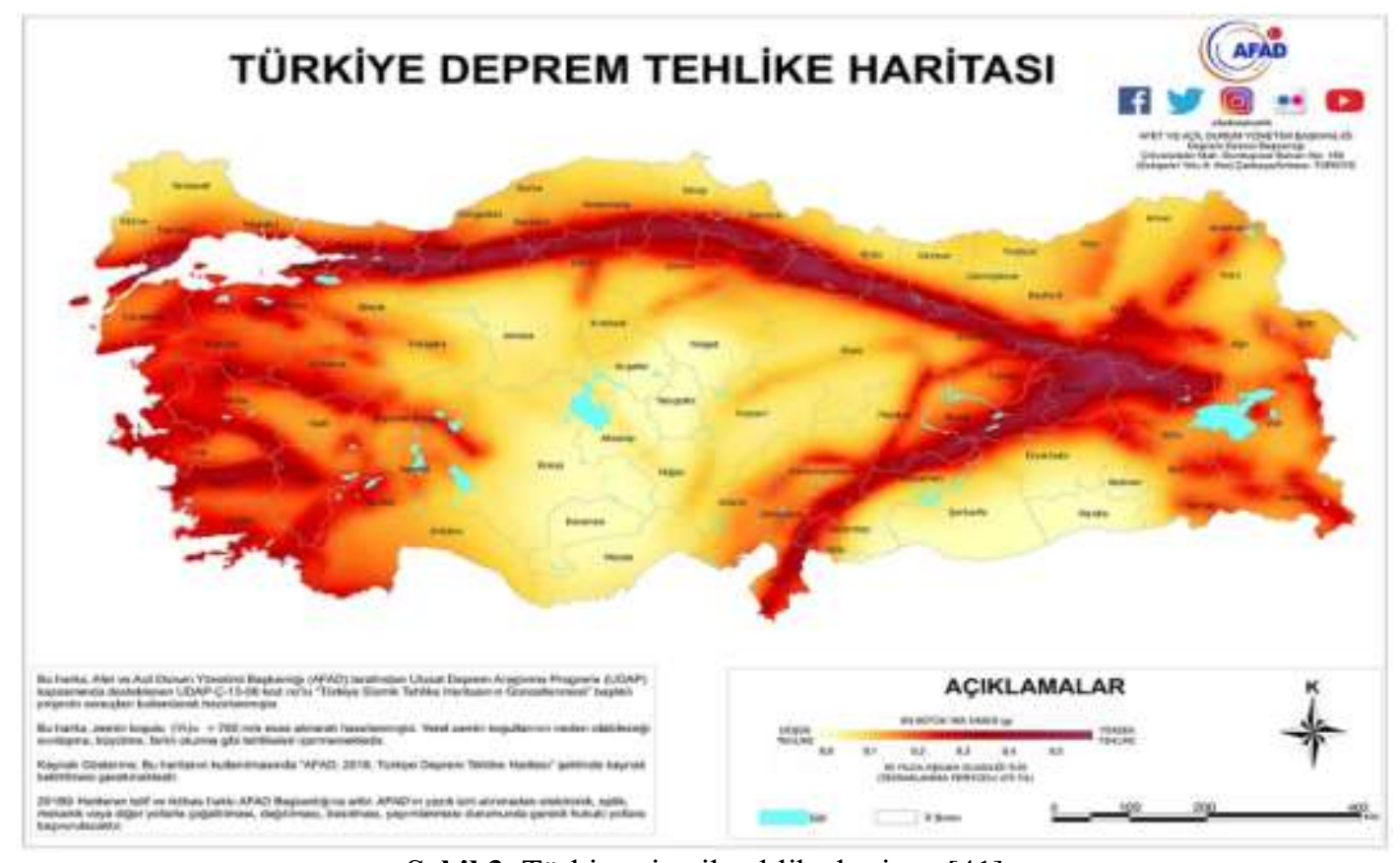

Şekil 3. Türkiye sismik tehlike haritası [41]

Türkiye Bina Deprem Yönetmeliği'nde (TBDY-2018), deprem yer hareket düzeyi önceki yönetmeliklerden farklı olarak dört farklı şekilde ifade edilmiştir. Çalışma kapsamında da kullanılan deprem yer hareket düzeyleri Tablo 4'te verilmiştir. Dört farklı deprem yer hareket düzeyi için deprem parametre değerleri ayrı ayrı hesaplanmıştır.

Tablo 4. Deprem yer hareketi düzeyleri [40]

\begin{tabular}{cccc}
\hline Deprem Düzeyi & $\begin{array}{c}\text { Tekrarlanma } \\
\text { Periyodu }\end{array}$ & $\begin{array}{c}\text { Aşılma Olasılı̆̆ }(50 \\
\text { yılda) }\end{array}$ & Tanımı \\
\hline DD-1 & 2475 & 0.02 & En büyük deprem yer hareketi \\
DD-2 & 475 & 0.1 & Standart tasarım deprem yer hareketi \\
DD-3 & 72 & 0.5 & Sik deprem yer hareketi \\
DD-4 & 43 & 0.68 & Servis deprem hareketi \\
\hline
\end{tabular}

Türkiye Deprem Tehlike Haritaları İnteraktif Web Uygulaması kullanılarak Sivrice ve Pütürge için dikkate alınan konumların her biri için farklı deprem yer hareket düzeyleri için en büyük yer ivmesi $\left(\mathrm{P}_{\mathrm{GA}}\right)$, en büyük yer hızı $\left(\mathrm{P}_{\mathrm{GV}}\right)$ değerlerinin karşılaştırılması Tablo 5 'te gösterilmiştir. 
Tablo 5. Farklı aşılma olasılıkları için elde edilen PGA ve PGV değerleri

\begin{tabular}{lllllllll}
\hline \multirow{2}{*}{ İlçe } & \multicolumn{3}{c}{$\begin{array}{c}\text { En büyük yer ivmesi (g) } \\
\text { 50 yılda aşılma olasılığı }\end{array}$} & \multicolumn{4}{c}{$\begin{array}{c}\text { En büyük yer hızı (cm/s)-PGV } \\
\text { 50 yılda aşılma olasılığı }\end{array}$} \\
\cline { 2 - 9 } Sivrice & $2 \%$ & $10 \%$ & $50 \%$ & $68 \%$ & $2 \%$ & $10 \%$ & $50 \%$ & $68 \%$ \\
Pütürge & 1.165 & 0.665 & 0.250 & 0.149 & 94.266 & 52.212 & 13.765 & 7.456 \\
\hline
\end{tabular}

Çalışmada dikkate alınan konumlar için uygulama üzerinden elde edilen farklı aşılma olasılıkları için en büyük yer ivme haritaları Şekil 4'te gösterilmiştir.

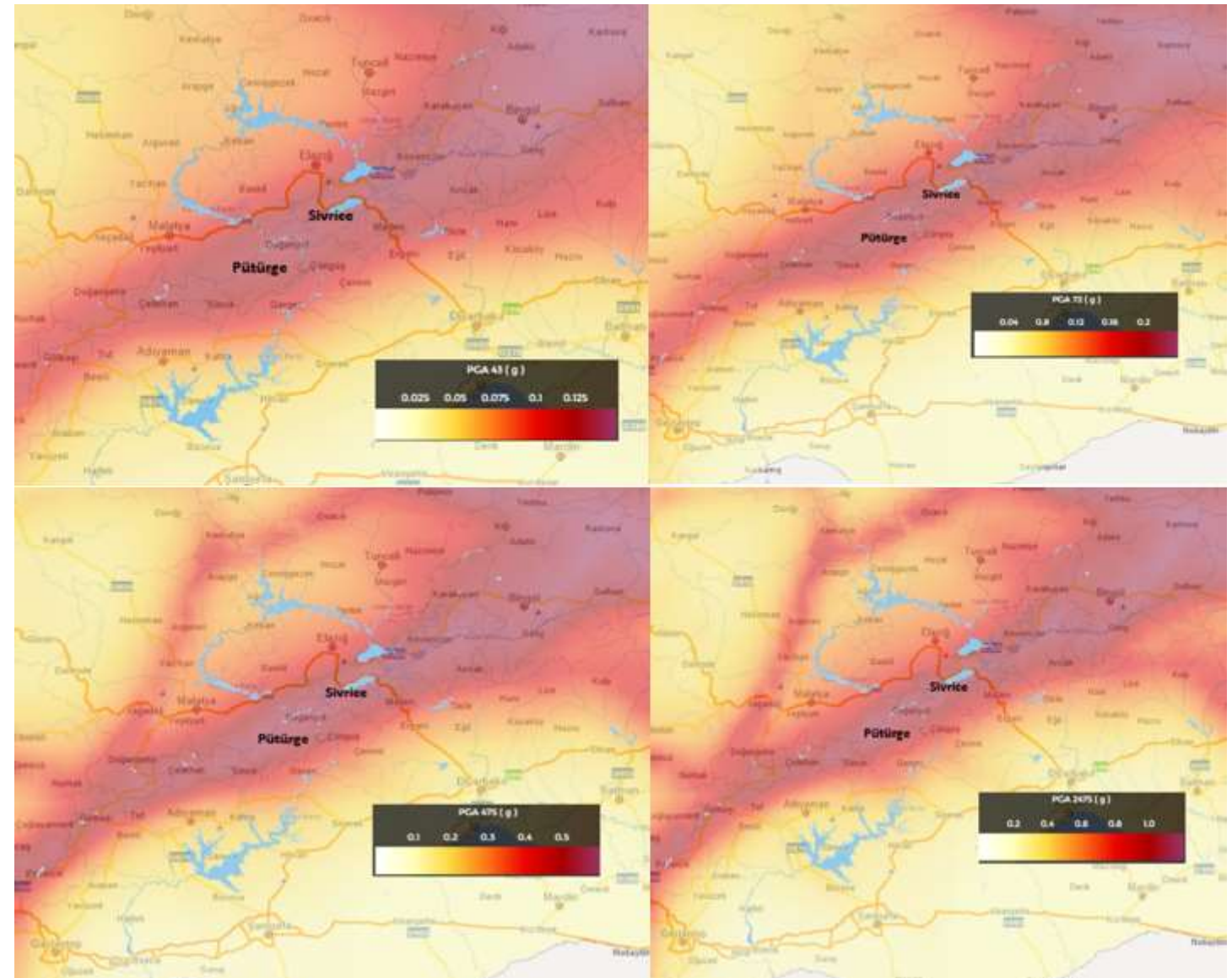

Şekil 4. Farklı aşılma olasılıkları için en büyük ivme değerlerini gösteren haritalar

Türkiye Deprem Tehlike Haritaları İnteraktif Web Uygulaması [41] kullanılarak Sivrice ve Pütürge için farklı deprem yer hareket düzeyleri için kısa periyot harita spektral ivme katsayısı $\left(\mathrm{S}_{\mathrm{S}}\right), 1.0$ saniye periyot için harita spektral ivme katsayısı $\left(\mathrm{S}_{1}\right)$, değerlerinin karşılaştırılması Tablo 6'da gösterilmiştir.

Tablo 6. Farklı aşılma olasılıkları için elde edilen $\mathrm{S}_{\mathrm{S}}$ ve $\mathrm{S}_{1}$ değerleri

\begin{tabular}{|c|c|c|c|c|c|c|c|c|}
\hline \multirow[t]{2}{*}{ İlçe } & \multicolumn{4}{|c|}{$\begin{array}{c}\text { Kısa periyot ivme katsayısı }\left(\mathrm{S}_{\mathrm{s}}\right) \\
50 \text { yılda aşılma olasılığı }\end{array}$} & \multicolumn{4}{|c|}{$\begin{array}{c}1.0 \text { saniye periyot için harita spektral } \\
\text { ivme katsayısı }\left(S_{1}\right) \\
50 \text { yılda aşılma olasılığı }\end{array}$} \\
\hline & $2 \%$ & $10 \%$ & $50 \%$ & $68 \%$ & $2 \%$ & $10 \%$ & $50 \%$ & $68 \%$ \\
\hline Sivrice & 2.913 & 1.604 & 0.578 & 0.339 & 0.819 & 0.419 & 0.132 & 0.074 \\
\hline Pütürge & 2.884 & 1.580 & 0.521 & 0.314 & 0.785 & 0.406 & 0.116 & 0.066 \\
\hline
\end{tabular}

Bir önceki deprem yönetmeliğinde zemin grup ve sınıfları ayrı ayrı ifade edilirken güncel yönetmelik ile zemin sınıf ve grupları birleştirilmiştir. Güncel deprem yönetmeliğinde yer alan zemin sinıfları ve özellikleri Tablo 7'de verilmiştir. 
Tablo 7. Yerel zemin sinıfları [40]

\begin{tabular}{|c|c|c|c|c|}
\hline \multirow{2}{*}{$\begin{array}{c}\text { Yerel } \\
\text { Zemin } \\
\text { Sinıfi }\end{array}$} & \multirow[b]{2}{*}{ Zemin Cinsi } & \multicolumn{3}{|c|}{ Üst 30 metrede ortalama } \\
\hline & & $\begin{array}{l}\left(V_{\mathrm{s}}\right)_{30} \\
{[\mathrm{~m} / \mathrm{s}]}\end{array}$ & $\begin{array}{c}\left(N_{60}\right)_{30} \\
\text { [darbe } / 30 \mathrm{~cm} \text { ] }\end{array}$ & $\begin{array}{l}\left(c_{\mathrm{u}}\right)_{30} \\
{[\mathrm{kPa}]}\end{array}$ \\
\hline $\mathrm{ZA}$ & Sağlam, sert kayalar & $>1500$ & - & - \\
\hline ZB & Az ayrışmış, orta sağlam kayalar & $760-1500$ & - & - \\
\hline $\mathrm{ZC}$ & $\begin{array}{l}\text { Çok sıkı kum, çakıl ve sert kil tabakaları veya } \\
\text { ayrıșmıș, çok çatlaklı zayıf kayalar }\end{array}$ & $360-760$ & $>50$ & $>250$ \\
\hline $\mathrm{ZD}$ & $\begin{array}{l}\text { Orta sıkı - sıkı kum, çakıl veya çok katı kil } \\
\text { tabakaları }\end{array}$ & $180-360$ & $15-50$ & $70-250$ \\
\hline ZE & $\begin{array}{l}\text { Gevșek kum, çakıl veya yumușak - katı kil } \\
\text { tabakaları veya } \\
P I>20 \text { ve } w>\% 40 \text { koșullarını sağlayan } \\
\text { toplamda } 3 \text { metreden daha kalın yumuşak kil } \\
\text { tabakası }\left(c_{\mathrm{u}}<25 \mathrm{kPa}\right) \text { içeren profiller }\end{array}$ & $<180$ & $<15$ & $<70$ \\
\hline $\mathrm{ZF}$ & \multicolumn{4}{|c|}{$\begin{array}{l}\text { Sahaya özel araștırma ve değerlendirme gerektiren zeminler: } \\
\text { 1) Deprem etkisi altında çökme ve potansiyel göçme riskine sahip zeminler (sıvılașabilir zeminler, } \\
\text { yüksek derecede hassas killer, göçebilir zayıf çimentolu zeminler vb.), } \\
\text { 2) Toplam kalınlığı } 3 \text { metreden fazla turba ve/veya organik içeriği yüksek killer, } \\
\text { 3) Toplam kalınlığı } 8 \text { metreden fazla olan yüksek plastisiteli }(P I>50) \text { killer, } \\
\text { 4) Çok kalın }(>35 \mathrm{~m}) \text { yumuşak veya orta katı killer. }\end{array}$} \\
\hline
\end{tabular}

Türkiye Deprem Tehlike Haritaları İnteraktif Web Uygulaması [41] kullanılarak TBDY2018'de yer alan dört farklı yer hareket düzeyi ve beş farklı yerel zemin sınıfı değişken olarak seçilerek deprem parametreleri ve tasarım spektrumları uygulama üzerinden ayrı ayrı elde edilmiştir. Yerel zemin etki katsayıları $\left(\mathrm{F}_{\mathrm{S}}\right.$ ve $\left.\mathrm{F}_{1}\right)$, tasarım spektral ivme katsayıları (kısa periyot tasarım spektral ivme katsayısı $\left(\mathrm{S}_{\mathrm{DS}}\right)$ ile 1.0 saniye periyot için tasarım spektral ivme katsayısı $\left(\mathrm{S}_{\mathrm{D} 1}\right)$ ve yatay ile düşey elastik spektrum değerleri ayrı ayrı elde edilmiştir. Farklı yer hareket düzeyleri ve zemin sınıfları için elde edilen değerlerin karşılaştırılması Tablo 8'de verilmiştir.

Tablo 8. Deprem parametre değerlerinin farklı yer hareketleri ve zemin sınıfları için karşılaştırılması

\begin{tabular}{lccccccccc}
\hline $\begin{array}{l}\text { Zemin } \\
\text { Sinıfi }\end{array}$ & Parametre & \multicolumn{2}{c}{ DD-1 } & \multicolumn{2}{c}{ DD-2 } & \multicolumn{2}{c}{ DD-3 } & \multicolumn{2}{c}{ DD-4 } \\
& & Sivrice & Pütürge & Sivrice & Pütürge & Sivrice & Pütürge & Sivrice & Pütürge \\
\hline & $\mathrm{F}_{\mathrm{S}}$ & 0.800 & 0.800 & 0.800 & 0.800 & 0.800 & 0.800 & 0.800 & 0.800 \\
& $\mathrm{~F}_{1}$ & 0.800 & 0.800 & 0.800 & 0.800 & 0.800 & 0.800 & 0.800 & 0.800 \\
& $\mathrm{~S}_{\mathrm{DS}}$ & 2.330 & 2.307 & 1.283 & 1.264 & 0.462 & 0.417 & 0.271 & 0.251 \\
& $\mathrm{~S}_{\mathrm{D} 1}$ & 0.655 & 0.628 & 0.335 & 0.325 & 0.106 & 0.093 & 0.059 & 0.053 \\
& $\mathrm{~T}_{\mathrm{A}}$ & 0.056 & 0.054 & 0.052 & 0.051 & 0.046 & 0.045 & 0.044 & 0.042 \\
& $\mathrm{~T}_{\mathrm{B}}$ & 0.281 & 0.272 & 0.261 & 0.257 & 0.228 & 0.223 & 0.218 & 0.210 \\
& $\mathrm{~T}_{\mathrm{AD}}$ & 0.019 & 0.018 & 0.017 & 0.017 & 0.015 & 0.015 & 0.015 & 0.014 \\
& $\mathrm{~T}_{\mathrm{BD}}$ & 0.094 & 0.091 & 0.087 & 0.086 & 0.076 & 0.074 & 0.073 & 0.070 \\
& $\mathrm{~F}_{\mathrm{S}}$ & 0.900 & 0.900 & 0.900 & 0.900 & 0.900 & 0.900 & 0.900 & 0.900 \\
& $\mathrm{~F}_{1}$ & 0.800 & 0.800 & 0.800 & 0.800 & 0.800 & 0.800 & 0.800 & 0.800 \\
& $\mathrm{~S}_{\mathrm{DS}}$ & 2.622 & 2.596 & 1.444 & 1.422 & 0.520 & 0.469 & 0.305 & 0.283 \\
& $\mathrm{~S}_{\mathrm{D} 1}$ & 0.655 & 0.628 & 0.335 & 0.325 & 0.106 & 0.093 & 0.059 & 0.053 \\
& $\mathrm{~T}_{\mathrm{A}}$ & 0.050 & 0.048 & 0.046 & 0.046 & 0.041 & 0.040 & 0.039 & 0.037 \\
& $\mathrm{~T}_{\mathrm{B}}$ & 0.250 & 0.242 & 0.232 & 0.228 & 0.203 & 0.198 & 0.194 & 0.187 \\
& $\mathrm{~T}_{\mathrm{AD}}$ & 0.017 & 0.016 & 0.015 & 0.015 & 0.014 & 0.013 & 0.013 & 0.012 \\
& $\mathrm{~T}_{\mathrm{BD}}$ & 0.083 & 0.081 & 0.077 & 0.076 & 0.068 & 0.066 & 0.065 & 0.062 \\
& $\mathrm{~F}_{\mathrm{S}}$ & 1.200 & 1.200 & 1.200 & 1.200 & 1.269 & 1.290 & 1.300 & 1.300 \\
& $\mathrm{~F}_{1}$ & 1.400 & 1.400 & 1.500 & 1.500 & 1.500 & 1.500 & 1.500 & 1.500 \\
$\mathrm{ZC}$ & $\mathrm{S}_{\mathrm{DS}}$ & 3.496 & 3.461 & 1.925 & 1.896 & 0.733 & 0.673 & 0.441 & 0.408 \\
& $\mathrm{~S}_{\mathrm{D} 1}$ & 1.147 & 1.099 & 0.628 & 0.609 & 0.198 & 0.174 & 0.111 & 0.099 \\
& $\mathrm{~T}_{\mathrm{A}}$ & 0.066 & 0.064 & 0.065 & 0.064 & 0.054 & 0.052 & 0.050 & 0.049 \\
& $\mathrm{~T}_{\mathrm{B}}$ & 0.328 & 0.318 & 0.327 & 0.321 & 0.270 & 0.259 & 0.252 & 0.243 \\
\hline
\end{tabular}




\begin{tabular}{|c|c|c|c|c|c|c|c|c|c|}
\hline & $\mathrm{T}_{\mathrm{AD}}$ & 0.022 & 0.021 & 0.022 & 0.021 & 0.018 & 0.017 & 0.017 & 0.016 \\
\hline & $\mathrm{T}_{\mathrm{BD}}$ & 0.109 & 0.106 & 0.109 & 0.107 & 0.090 & 0.086 & 0.084 & 0.081 \\
\hline \multirow{8}{*}{ ZD } & $\mathrm{F}_{\mathrm{S}}$ & 1.000 & 1.000 & 1.000 & 1.000 & 1.338 & 1.383 & 1.529 & 1.549 \\
\hline & $\mathrm{F}_{1}$ & 1.700 & 1.700 & 1.881 & 1.894 & 2.336 & 2.368 & 2.400 & 2.400 \\
\hline & $S_{D S}$ & 2.913 & 2.884 & 1.604 & 1.580 & 0.773 & 0.721 & 0.518 & 0.486 \\
\hline & $S_{D 1}$ & 1.392 & 1.335 & 0.788 & 0.769 & 0.308 & 0.275 & 0.178 & 0.158 \\
\hline & $\mathrm{T}_{\mathrm{A}}$ & 0.096 & 0.093 & 0.098 & 0.097 & 0.080 & 0.076 & 0.069 & 0.065 \\
\hline & $\mathrm{T}_{\mathrm{B}}$ & 0.478 & 0.463 & 0.491 & 0.487 & 0.399 & 0.381 & 0.343 & 0.326 \\
\hline & $\mathrm{T}_{\mathrm{AD}}$ & 0.032 & 0.031 & 0.033 & 0.032 & 0.027 & 0.025 & 0.023 & 0.022 \\
\hline & $\mathrm{T}_{\mathrm{BD}}$ & 0.159 & 0.154 & 0.164 & 0.162 & 0.133 & 0.127 & 0.114 & 0.109 \\
\hline \multirow{8}{*}{$\mathrm{ZE}$} & $\mathrm{F}_{\mathrm{S}}$ & 0.800 & 0.800 & 0.800 & 0.800 & 1.575 & 1.666 & 2.151 & 2.221 \\
\hline & $\mathrm{F}_{1}$ & 2.000 & 2.000 & 2.362 & 2.338 & 3.912 & 4.056 & 4.200 & 4.200 \\
\hline & $S_{D S}$ & 2.330 & 2.307 & 1.283 & 1.264 & 0.910 & 0.868 & 0.729 & 0.697 \\
\hline & $S_{D 1}$ & 1.638 & 1.570 & 0.990 & 0.970 & 0.516 & 0.470 & 0.311 & 0.277 \\
\hline & $\mathrm{T}_{\mathrm{A}}$ & 0.141 & 0.136 & 0.154 & 0.153 & 0.113 & 0.108 & 0.085 & 0.080 \\
\hline & $\mathrm{T}_{\mathrm{B}}$ & 0.703 & 0.680 & 0.771 & 0.767 & 0.567 & 0.542 & 0.426 & 0.398 \\
\hline & $\mathrm{T}_{\mathrm{AD}}$ & 0.047 & 0.045 & 0.051 & 0.051 & 0.038 & 0.036 & 0.028 & 0.027 \\
\hline & $\mathrm{T}_{\mathrm{BD}}$ & 0.234 & 0.227 & 0.257 & 0.256 & 0.189 & 0.181 & 0.142 & 0.133 \\
\hline
\end{tabular}

Spektral ivme katsayılarının karşılaştırılması sadece DD-2 yer hareket düzeyine göre yapılmıştır. Bunun sebebi bir önceki deprem yönetmeliğinde sadece tekrarlanma periyodu 475 y1l, 50 yılda aşılma olasılığ $1 \% 10$ olan yer hareket düzeyinin kullanılmasıdır. Bu yer hareket düzeyi dikkate alınarak, spektral ivme katsayılarının son iki deprem yönetmeliğine göre karşılaştırılması Tablo 9'da gösterilmiştir.

Tablo 9. Spektral ivme katsayılarının farklı zemin türleri ile karşılaştırılması

\begin{tabular}{|c|c|c|c|c|c|c|c|c|c|c|c|c|}
\hline \multirow{3}{*}{$\begin{array}{c}\text { Yerleşim } \\
\text { birimi }\end{array}$} & \multirow{2}{*}{\multicolumn{2}{|c|}{$\mathbf{Z A}$}} & \multirow{2}{*}{\multicolumn{2}{|c|}{ ZB }} & \multicolumn{4}{|c|}{ TBDY -2018 } & \multirow{2}{*}{\multicolumn{2}{|c|}{$\mathbf{Z E}$}} & \multirow{2}{*}{\multicolumn{2}{|c|}{$\begin{array}{c}\text { Tüm Zemin } \\
\text { sinıfları } \\
\text { DBYBHY- } \\
2007\end{array}$}} \\
\hline & & & & & & $\mathrm{ZC}$ & & ZD & & & & \\
\hline & $\mathrm{S}_{\mathrm{DS}}$ & $0.40 \mathrm{~S}_{\mathrm{Ds}}$ & $\mathrm{S}_{\mathrm{DS}}$ & $0.40 \mathrm{~S}_{\mathrm{Ds}}$ & $\mathrm{S}_{\mathrm{DS}}$ & $0.40 \mathrm{~S}_{\mathrm{Ds}}$ & $\mathrm{S}_{\mathrm{DS}}$ & $0.40 \mathrm{~S}_{\mathrm{Ds}}$ & $\mathrm{S}_{\mathrm{DS}}$ & $0.40 \mathrm{~S}_{\mathrm{Ds}}$ & $\mathrm{S}_{\mathrm{DS}}$ & $0.40 \mathrm{~S}_{\mathrm{Ds}}$ \\
\hline Pütürge & 1.264 & 0.506 & 1.422 & 0.569 & 1.896 & 0.759 & 1.580 & 0.632 & 1.264 & 0.506 & 1.00 & 0.40 \\
\hline Sivrice & 1.283 & 0.513 & 1.444 & 0.578 & 1.925 & 0.770 & 1.604 & 0.624 & 1.283 & 0.513 & 1.00 & 0.40 \\
\hline
\end{tabular}

Farklı zemin grupları için elde edilen yatay ve düşey tasarım spektrumlarının karşılaştııılması Sivrice için Şekil 5, Pütürge için Şekil 6' da verilmiştir.

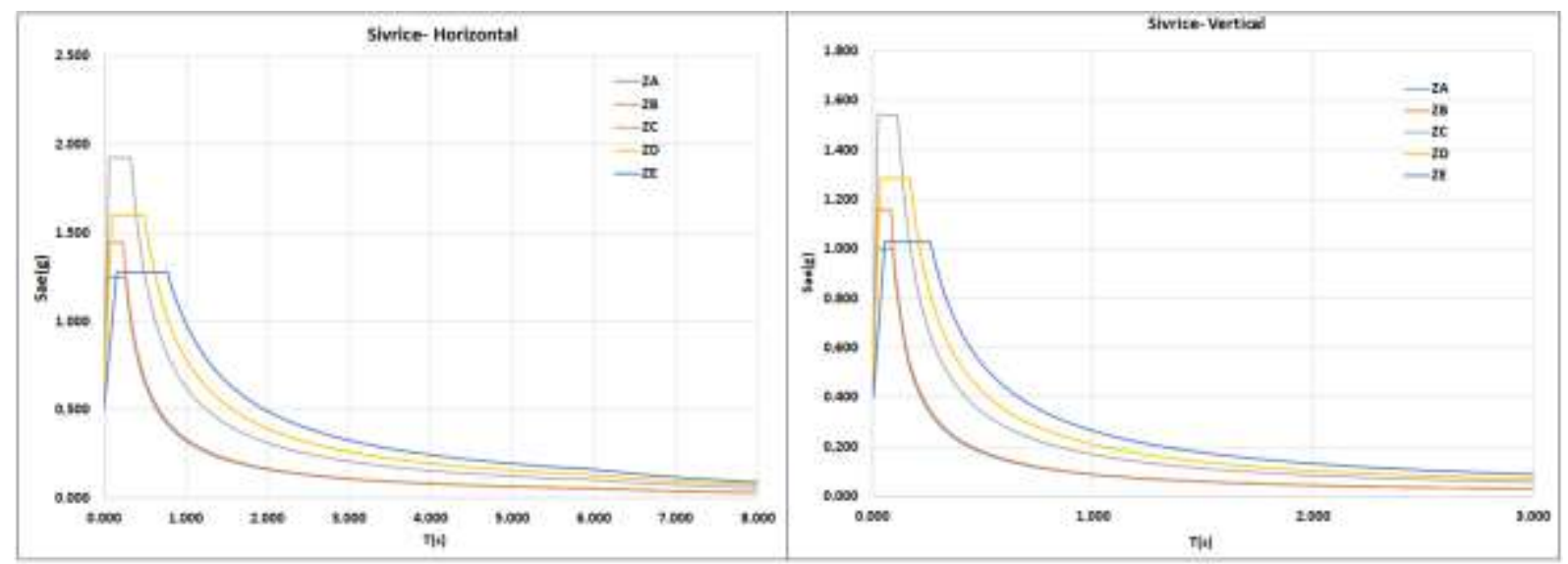

Şekil 5. Sivrice için farklı zemin sınıfları için DD-2 için elde edilen spektrumların karşılaştırılması 


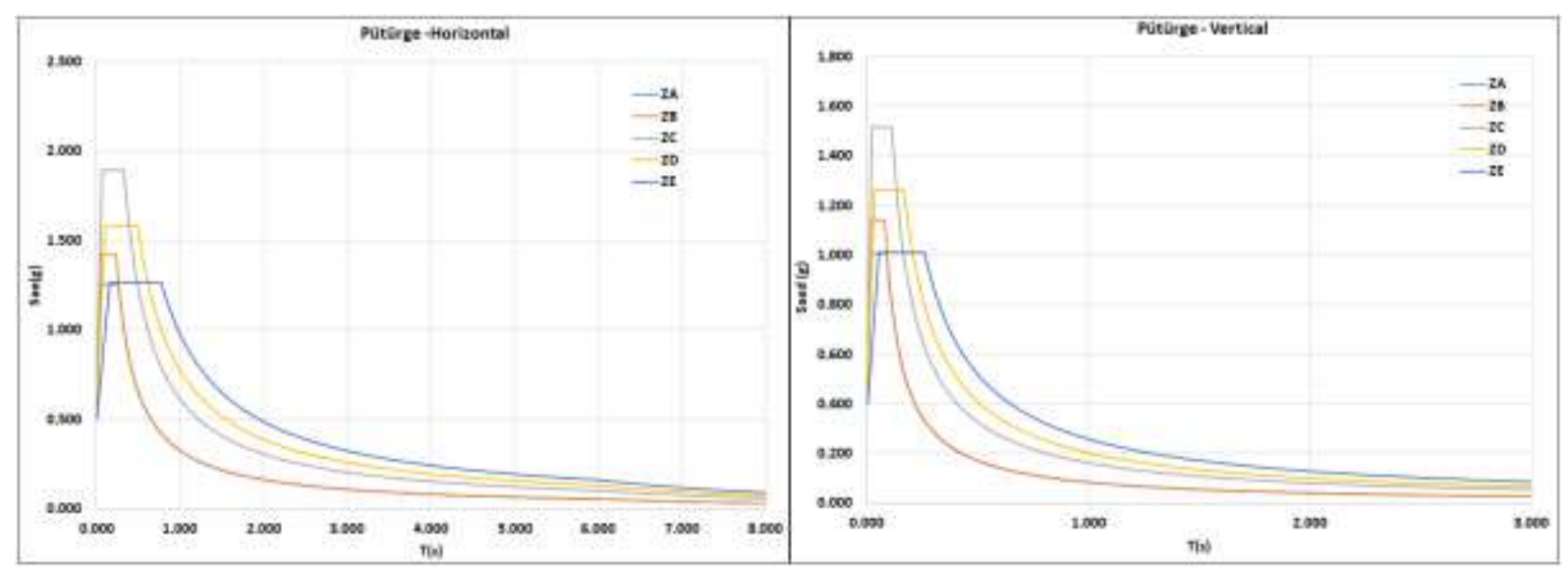

Şekil 6. Pütürge için farklı zemin sınıfları için DD-2 için elde edilen spektrumların karşılaştırılması

\section{4. Örnek Çelik Yapı Özellikleri}

Yapısal analizlerde yaygın olarak kullanılan SAP2000 yazılımı [42] ile analizler yapılmıştır. Bu yazılımın seçilmesindeki neden, güncel olan TBDY-2018 bu yazılıma entegre edilmesidir. Böylece yapıların deprem analizinde TBDY-2018'e uygun olarak dinamik analiz yapılmakta, hassas ve kesin sonuçlar elde edilmektedir. Bu çalışma kapsamında Sivrice ve Pütürge için interaktif web deprem uygulamasından elde edilen tasarım spektrumları kullanılarak yapısal analizler gerçekleştirilmiştir. Örnek olarak seçilen sekiz katlı çelik karkas bir bina dikkate alınmış olup kat yükseklikleri birbirine eşit olarak alınmıştır. Yapı x yönünde 5 açıklıklı ve her bir açıklığı 10m, y yönünde ise 7 açıklıklı ve her bir açıklığ $8 \mathrm{~m}$ olarak boyutlandırılmıştır. Yapı yüksekliği $24 \mathrm{~m}$ olup, kat yüksekliği 3m'dir. Bu yapıya ait 2 ve 3 boyutu yapisal modeller Şekil 7'de verilmiştir.

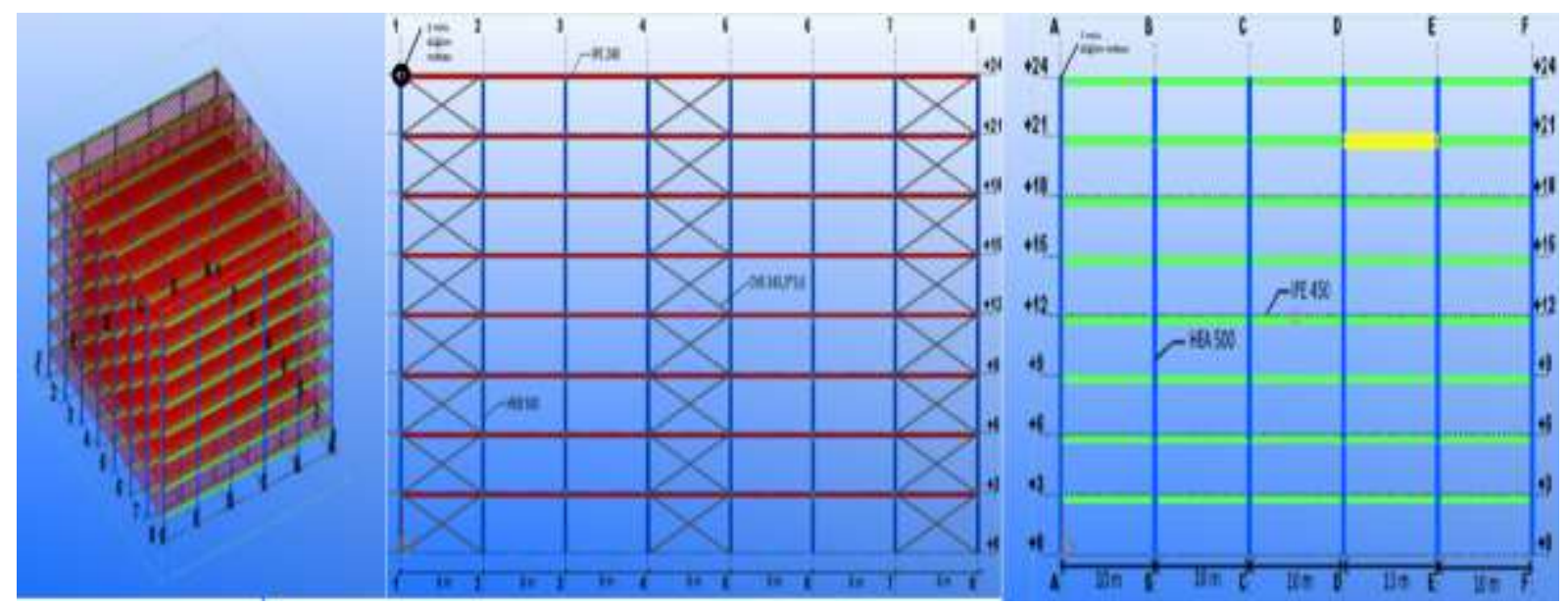

Şekil 7. Çelik yapı için elde edilen 2 ve 3 boyutlu modeller

Deprem etkisini güvenle karşılamak üzere, çelik çerçevelerin zayıf yönünde çapraz elemanlar yerleştirilmiştir. Çelik yapının ana kirişlerinde IPE450, kolonlarında HEB500, çaprazlarında TUBOD114.3X3.6 ve tali kirişlerinde ise IPE240 profilleri seçilmiştir. Yapının tasarımında, "2016-Çelik Yapıların Tasarım Hesap ve Yapım Esaslarına Dair Yönetmelik" [43] kriterleri göz önüne alınmıştır.

\section{Bulgular ve Tartışma}

Yapısal analizler sonucu örnek olarak seçilen çelik yapı doğal titreşim periyodu 1.947 s olarak hesaplanmıştır. $\mathrm{X}$,_Y ve $\mathrm{Z}$ yönündeki farklı deprem yüklemelerinden dolayı 2 nolu düğüm noktasında elde edilen yer değiştirme ve dönme değerleri Tablo 10'da gösterilmiştir. 
Tablo 10. Farklı yüklemeler altında farklı zemin koşulları için elde edilen yer değiştirme ve dönme değerleri

\begin{tabular}{|c|c|c|c|c|c|c|c|c|c|}
\hline $\begin{array}{c}\text { Yerleşim } \\
\text { Birimi }\end{array}$ & $\begin{array}{c}\text { Zemin } \\
\text { sinıfi }\end{array}$ & Nokta & $\begin{array}{l}\text { Yükleme } \\
\text { Durumu }\end{array}$ & $\begin{array}{l}\mathbf{U}_{\mathbf{X}} \\
(\mathbf{m})\end{array}$ & $\begin{array}{l}\mathbf{U}_{\mathbf{Y}} \\
(\mathbf{m})\end{array}$ & $\begin{array}{l}\mathbf{U}_{\mathbf{Z}} \\
(\mathbf{m})\end{array}$ & $\begin{array}{c}\mathbf{R}_{\mathbf{X}} \\
\text { (Radyan) }\end{array}$ & $\begin{array}{c}\mathbf{R}_{\mathbf{Y}} \\
\text { (Radyan) }\end{array}$ & $\begin{array}{c}\mathbf{R}_{\mathbf{Z}} \\
\text { (Radyan) }\end{array}$ \\
\hline \multirow{10}{*}{ 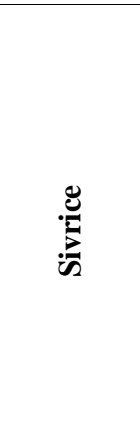 } & $\mathbf{Z A}$ & 2 & EX & 0.074896 & 0.005976 & 0.000654 & -0.000121 & 0.001371 & -0.000239 \\
\hline & $\mathbf{Z B}$ & 2 & EX & 0.084258 & 0.006723 & 0.000735 & -0.000136 & 0.001542 & -0.000269 \\
\hline & $\mathbf{Z C}$ & 2 & $\mathrm{EX}$ & 0.094695 & 0.007556 & 0.000826 & -0.000153 & 0.001733 & -0.000302 \\
\hline & ZD & 2 & EX & 0.112344 & 0.008964 & 0.00098 & -0.000181 & 0.002056 & -0.000359 \\
\hline & $\mathbf{Z E}$ & 2 & EX & 0.11891 & 0.009488 & 0.001038 & -0.000192 & 0.002177 & -0.00038 \\
\hline & $\mathbf{Z A}$ & 2 & EY & 0.005976 & 0.034084 & 0.001191 & -0.000686 & 0.000108 & 0.000213 \\
\hline & $\mathbf{Z B}$ & 2 & EY & 0.006723 & 0.038344 & 0.001339 & -0.000771 & 0.000121 & 0.00024 \\
\hline & $\mathrm{ZC}$ & 2 & EY & 0.010694 & 0.060993 & 0.002131 & -0.001227 & 0.000192 & 0.000382 \\
\hline & ZD & 2 & EY & 0.013411 & 0.076485 & 0.002672 & -0.001539 & 0.000241 & 0.000479 \\
\hline & $\mathbf{Z E}$ & 2 & EY & 0.01684 & 0.096043 & 0.003355 & -0.001932 & 0.000303 & 0.000601 \\
\hline \multirow{10}{*}{ 罚 } & $\mathbf{Z A}$ & 2 & EX & 0.073775 & 0.005887 & 0.000644 & -0.000119 & 0.00135 & -0.000235 \\
\hline & $\mathbf{Z B}$ & 2 & EX & 0.082997 & 0.006623 & 0.000724 & -0.000134 & 0.001519 & -0.000265 \\
\hline & $\mathbf{Z C}$ & 2 & EX & 0.092392 & 0.007372 & 0.000806 & -0.000149 & 0.001691 & -0.000295 \\
\hline & ZD & 2 & EX & 0.110663 & 0.00883 & 0.000966 & -0.000179 & 0.002026 & -0.000353 \\
\hline & $\mathbf{Z E}$ & 2 & EX & 0.116489 & 0.009295 & 0.001017 & -0.000188 & 0.002132 & -0.000372 \\
\hline & $\mathbf{Z A}$ & 2 & EY & 0.005887 & 0.033574 & 0.001173 & -0.000675 & 0.000106 & 0.00021 \\
\hline & ZB & 2 & EY & 0.006623 & 0.037771 & 0.001319 & -0.00076 & 0.000119 & 0.000237 \\
\hline & $\mathbf{Z C}$ & 2 & EY & 0.010363 & 0.0591 & 0.002065 & -0.001189 & 0.000186 & 0.00037 \\
\hline & ZD & 2 & EY & 0.013084 & 0.074624 & 0.002607 & -0.001501 & 0.000235 & 0.000467 \\
\hline & $\mathbf{Z E}$ & 2 & EY & 0.016497 & 0.094088 & 0.003287 & -0.001893 & 0.000297 & 0.000589 \\
\hline
\end{tabular}

$\mathrm{X}$ ve $\mathrm{Y}$ doğrultularında statik itme analiz sonucu elde edilen yer değiştirme ve dönme değerleri Tablo 11'de verilmiştir.

Tablo 11. Yerdeğiştirme ve dönme değerleri

\begin{tabular}{|c|c|c|c|c|c|c|c|c|c|}
\hline $\begin{array}{c}\text { Yerleşim } \\
\text { Birimi }\end{array}$ & $\begin{array}{c}\text { Zemin } \\
\text { sınıfi }\end{array}$ & Nokta & $\begin{array}{l}\text { Yükleme } \\
\text { Durumu }\end{array}$ & $\begin{array}{r}\mathbf{U}_{\mathbf{X}} \\
(\mathbf{m})\end{array}$ & $\begin{array}{l}\mathbf{U}_{\mathbf{Y}} \\
(\mathbf{m})\end{array}$ & $\begin{array}{r}\mathbf{U}_{\mathbf{Z}} \\
(\mathbf{m})\end{array}$ & $\begin{array}{c}\mathbf{R}_{\mathbf{X}} \\
\text { (Radyan) }\end{array}$ & $\begin{array}{c}\mathbf{R}_{\mathbf{Y}} \\
\text { (Radyan) }\end{array}$ & $\begin{array}{c}\mathbf{R}_{\mathrm{Z}} \\
\text { (Radyan) }\end{array}$ \\
\hline \multirow{10}{*}{ 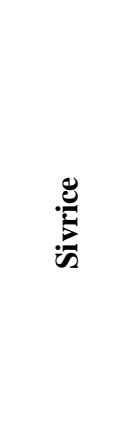 } & $\mathbf{Z A}$ & 2 & SPECX & 0.026625 & $7.02 \mathrm{E}-11$ & 0.00016 & $6.057 \mathrm{E}-11$ & 0.00065 & $1.549 \mathrm{E}-12$ \\
\hline & $\mathbf{Z B}$ & 2 & SPECX & 0.026626 & $7.22 \mathrm{E}-11$ & 0.00016 & $6.084 \mathrm{E}-11$ & 0.000654 & $1.594 \mathrm{E}-12$ \\
\hline & $\mathbf{Z C}$ & 2 & SPECX & 0.049919 & $1.19 \mathrm{E}-10$ & 0.0003 & $1.121 \mathrm{E}-10$ & 0.001199 & $2.632 \mathrm{E}-12$ \\
\hline & ZD & 2 & SPECX & 0.062578 & $1.28 \mathrm{E}-10$ & 0.000376 & $1.378 \mathrm{E}-10$ & 0.001421 & $2.861 \mathrm{E}-12$ \\
\hline & $\mathbf{Z E}$ & 2 & SPECX & 0.078386 & $1.23 \mathrm{E}-10$ & 0.000463 & $1.34 \mathrm{E}-10$ & 0.001584 & $2.868 \mathrm{E}-12$ \\
\hline & $\mathbf{Z A}$ & 2 & SPECY & 3.32E-10 & 0.030008 & 0.001057 & 0.000695 & 6.19E-06 & $9.571 \mathrm{E}-12$ \\
\hline & ZB & 2 & SPECY & $3.35 \mathrm{E}-10$ & 0.03001 & 0.001057 & 0.000699 & $6.28 \mathrm{E}-06$ & $9.616 \mathrm{E}-12$ \\
\hline & $\mathbf{Z C}$ & 2 & SPECY & $6.35 \mathrm{E}-10$ & 0.056302 & 0.001995 & 0.001298 & 0.000011 & $1.867 \mathrm{E}-11$ \\
\hline & ZD & 2 & SPECY & $6.87 \mathrm{E}-10$ & 0.07045 & 0.002452 & 0.001499 & 0.000012 & $1.968 \mathrm{E}-11$ \\
\hline & $\mathbf{Z E}$ & 2 & SPECY & $5.77 \mathrm{E}-10$ & 0.088196 & 0.002987 & 0.001679 & $9.7 \mathrm{E}-06$ & $1.586 \mathrm{E}-11$ \\
\hline \multirow{10}{*}{ : } & $\mathbf{Z A}$ & 2 & SPECX & 0.025799 & $6.85 \mathrm{E}-11$ & 0.000155 & $5.876 \mathrm{E}-11$ & 0.00063 & $1.514 \mathrm{E}-12$ \\
\hline & $\mathbf{Z B}$ & 2 & SPECX & 0.02580 & $7.02 \mathrm{E}-11$ & 0.000155 & $5.898 \mathrm{E}-11$ & 0.000635 & $1.55 \mathrm{E}-12$ \\
\hline & $\mathbf{Z C}$ & 2 & SPECX & 0.048371 & $1.16 \mathrm{E}-10$ & 0.000291 & $1.088 \mathrm{E}-10$ & 0.001165 & $2.569 \mathrm{E}-12$ \\
\hline & ZD & 2 & SPECX & 0.061056 & $1.25 \mathrm{E}-10$ & 0.000367 & $1.345 \mathrm{E}-10$ & 0.001388 & $2.799 \mathrm{E}-12$ \\
\hline & $\mathbf{Z E}$ & 2 & SPECX & 0.076793 & $1.21 \mathrm{E}-10$ & 0.000453 & $1.32 \mathrm{E}-10$ & 0.001555 & $2.819 \mathrm{E}-12$ \\
\hline & $\mathbf{Z A}$ & 2 & SPECY & $3.23 \mathrm{E}-10$ & 0.029078 & 0.001024 & 0.000674 & $6.01 \mathrm{E}-06$ & $9.287 \mathrm{E}-12$ \\
\hline & ZB & 2 & SPECY & $3.24 \mathrm{E}-10$ & 0.029079 & 0.001024 & 0.000678 & $6.1 \mathrm{E}-06$ & $9.323 \mathrm{E}-12$ \\
\hline & $\mathbf{Z C}$ & 2 & SPECY & $6.19 \mathrm{E}-10$ & 0.05456 & 0.001934 & 0.001262 & 0.000011 & $1.819 \mathrm{E}-11$ \\
\hline & ZD & 2 & SPECY & $6.75 \mathrm{E}-10$ & 0.068743 & 0.002395 & 0.001468 & 0.000011 & $1.939 \mathrm{E}-11$ \\
\hline & $\mathbf{Z E}$ & 2 & SPECY & $5.69 \mathrm{E}-10$ & 0.086402 & 0.002927 & 0.001646 & $9.55 \mathrm{E}-06$ & $1.562 \mathrm{E}-11$ \\
\hline
\end{tabular}

Bir önceki deprem yönetmeliğinde verilen tasarım spektrum kullanılarak elde edilen yer değiştirme ve dönme değerleri Tablo 12'de gösterilmiştir. 
Tablo 12. DBYBHY-2007 için elde edilen yerdeğiştirme ve dönmeler

\begin{tabular}{cccccccccc}
\hline $\begin{array}{c}\text { Yerleşim } \\
\text { Birimi }\end{array}$ & $\begin{array}{c}\text { Zemin } \\
\text { Sinıfi }\end{array}$ & Nokta & $\begin{array}{c}\text { Yükleme } \\
\text { Durumu }\end{array}$ & $\begin{array}{c}\mathbf{U}_{\mathbf{X}} \\
(\mathbf{m})\end{array}$ & $\begin{array}{c}\mathbf{U}_{\mathbf{Y}} \\
(\mathbf{m})\end{array}$ & $\begin{array}{c}\mathbf{U}_{\mathbf{Z}} \\
(\mathbf{m})\end{array}$ & $\begin{array}{c}\mathbf{R}_{\mathbf{X}} \\
\text { (Radyan) }\end{array}$ & $\begin{array}{c}\mathbf{R}_{\mathbf{Y}} \\
\text { (Radyan) }\end{array}$ & $\begin{array}{c}\mathbf{R}_{\mathbf{Z}} \\
\text { (Radyan) }\end{array}$ \\
\hline & $\mathbf{Z 1}$ & 2 & SPECX & 0.001733 & $3.24 \mathrm{E}-12$ & 0.00001 & $3.069 \mathrm{E}-12$ & 0.000037 & $7.388 \mathrm{E}-14$ \\
& $\mathbf{Z 2}$ & 2 & SPECX & 0.002182 & $3.76 \mathrm{E}-12$ & 0.000013 & $3.827 \mathrm{E}-12$ & 0.000045 & $8.685 \mathrm{E}-14$ \\
& $\mathbf{Z 3}$ & 2 & SPECX & 0.003017 & $4.78 \mathrm{E}-12$ & 0.000018 & $5.218 \mathrm{E}-12$ & 0.000061 & $1.11 \mathrm{E}-13$ \\
& $\mathbf{Z 4}$ & 2 & SPECX & 0.004166 & $5.19 \mathrm{E}-12$ & 0.000024 & $5.312 \mathrm{E}-12$ & 0.000077 & $1.287 \mathrm{E}-13$ \\
& $\mathbf{Z 1}$ & 2 & SPECY & $2.51 \mathrm{E}-11$ & 0.002959 & 0.000102 & 0.000061 & $4.51 \mathrm{E}-07$ & $7.192 \mathrm{E}-13$ \\
& $\mathbf{Z 2}$ & 2 & SPECY & $3.11 \mathrm{E}-11$ & 0.003725 & 0.000128 & 0.000076 & $5.4 \mathrm{E}-07$ & $8.96 \mathrm{E}-13$ \\
& $\mathbf{Z 3}$ & 2 & SPECY & $3.6 \mathrm{E}-11$ & 0.005145 & 0.000175 & 0.000099 & $5.99 \mathrm{E}-07$ & $9.872 \mathrm{E}-13$ \\
& $\mathbf{Z 4}$ & 2 & SPECY & $3.61 \mathrm{E}-11$ & 0.007109 & 0.000239 & 0.000131 & $6.34 \mathrm{E}-07$ & $9.964 \mathrm{E}-13$ \\
\hline
\end{tabular}

X, Y ve Z doğrultularında statik yükleme sonucu TBDY-2018'de verilen yerel zemin koşulları için elde edilen global taban kesme kuvvet ve moment değerleri Tablo 13'te gösterilmişsir.

Tablo 13. Yerel zemin koşulları için elde edilen kuvvet ve moment değerleri

\begin{tabular}{|c|c|c|c|c|c|c|c|c|}
\hline $\begin{array}{c}\text { Yerleşim } \\
\text { Birimi }\end{array}$ & $\begin{array}{c}\text { Zemin } \\
\text { Sinıfi }\end{array}$ & $\begin{array}{l}\text { Yükleme } \\
\text { Durumu }\end{array}$ & $\begin{array}{c}\text { Global } \mathbf{F}_{\mathbf{X}} \\
(\mathrm{kN})\end{array}$ & 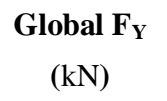 & $\begin{array}{c}\text { Global } \mathbf{F}_{\mathbf{Z}} \\
(\mathrm{kN})\end{array}$ & $\begin{array}{c}\text { Global } \mathbf{M}_{\mathbf{X}} \\
\quad(\mathrm{kN}-\mathrm{m})\end{array}$ & $\begin{array}{c}\text { Global } \mathbf{M}_{\mathbf{Y}} \\
(\mathrm{kN}-\mathrm{m})\end{array}$ & $\begin{array}{c}\text { Global } \mathbf{M}_{\mathbf{Z}} \\
(\mathrm{kN}-\mathrm{m})\end{array}$ \\
\hline \multirow{10}{*}{ 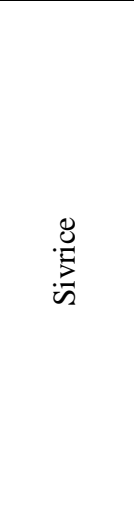 } & \multirow{2}{*}{$\mathrm{ZA}$} & EX & -4650.315 & $-7.39 \mathrm{E}-13$ & $7.85 \mathrm{E}-13$ & $-1.40 \mathrm{E}-10$ & -80430.249 & 143229.7 \\
\hline & & EY & $9.95 \mathrm{E}-12$ & -4650.315 & $-2.00 \mathrm{E}-11$ & 80430.2491 & $8.04 \mathrm{E}-10$ & -127883.7 \\
\hline & \multirow{2}{*}{ ZB } & EX & -5231.604 & $-7.598 \mathrm{E}-13$ & 4.995E-13 & $-1.621 \mathrm{E}-10$ & -90484.03 & 161133.41 \\
\hline & & EY & $1.119 \mathrm{E}-11$ & -5231.604 & $-1.905 \mathrm{E}-11$ & 90484.0302 & $7.581 \mathrm{E}-10$ & -143869.1 \\
\hline & \multirow{2}{*}{$\mathrm{ZC}$} & EX & -5879.689 & $-9.376 \mathrm{E}-13$ & 4.067E-12 & $-9.361 \mathrm{E}-11$ & -101693.09 & 181094.43 \\
\hline & & EY & $2.242 \mathrm{E}-11$ & -10435.35 & $-4.11 \mathrm{E}-11$ & 180486.336 & $1.662 \mathrm{E}-09$ & -286972.3 \\
\hline & \multirow{2}{*}{$\mathrm{ZD}$} & EX & -6975.472 & $-1.018 \mathrm{E}-12$ & $2.694 \mathrm{E}-12$ & $-1.473 \mathrm{E}-10$ & -120645.37 & 214844.55 \\
\hline & & EY & $1.774 \mathrm{E}-11$ & -8321.656 & $-3.282 \mathrm{E}-11$ & 143928.497 & $1.315 \mathrm{E}-09$ & -228845.5 \\
\hline & \multirow{2}{*}{$\mathrm{ZE}$} & EX & -7383.214 & $-1.055 \mathrm{E}-12$ & $2.265 \mathrm{E}-12$ & $-2.112 \mathrm{E}-10$ & -127697.54 & 227403 \\
\hline & & EY & $2.804 \mathrm{E}-11$ & -13103.83 & $-4.881 \mathrm{E}-11$ & 226639.407 & $1.909 \mathrm{E}-09$ & -360355.4 \\
\hline \multirow{10}{*}{ 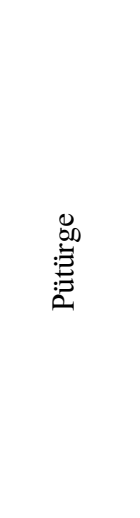 } & \multirow{2}{*}{$\mathrm{ZA}$} & EX & -4580.734 & $-7.303 \mathrm{E}-13$ & $6.243 \mathrm{E}-13$ & $-1.062 \mathrm{E}-10$ & -79226.804 & 141086.61 \\
\hline & & EY & $9.822 \mathrm{E}-12$ & -4580.734 & $-1.712 \mathrm{E}-11$ & 79226.8039 & 7.307E-10 & -125970.2 \\
\hline & \multirow{2}{*}{$\mathrm{ZB}$} & EX & -5153.326 & $-8.278 \mathrm{E}-13$ & $1.873 \mathrm{E}-12$ & $-1.222 \mathrm{E}-10$ & -89130.154 & 158722.44 \\
\hline & & EY & $1.107 \mathrm{E}-11$ & -5153.326 & $-1.912 \mathrm{E}-11$ & 89130.1544 & $8.083 \mathrm{E}-10$ & -141716.5 \\
\hline & \multirow{2}{*}{$\mathrm{ZC}$} & EX & -5736.64 & $-8.919 \mathrm{E}-13$ & $3.3 \mathrm{E}-12$ & $-1.313 \mathrm{E}-10$ & -99218.95 & 176688.5 \\
\hline & & EY & $2.195 \mathrm{E}-11$ & -10181.46 & $-3.796 \mathrm{E}-11$ & 176095.2 & $1.534 \mathrm{E}-09$ & -279990.4 \\
\hline & \multirow{2}{*}{ ZD } & $\mathrm{EX}$ & -6871.101 & $-1.016 \mathrm{E}-12$ & $4.049 \mathrm{E}-12$ & $-1.199 \mathrm{E}-10$ & -118840.21 & 211629.91 \\
\hline & & EY & $1.722 \mathrm{E}-11$ & -8063.466 & $-2.868 \mathrm{E}-11$ & 139462.935 & $1.352 \mathrm{E}-09$ & -221745.3 \\
\hline & \multirow{2}{*}{$\mathrm{ZE}$} & EX & -7232.891 & $-1.128 \mathrm{E}-12$ & $3.585 \mathrm{E}-12$ & $-1.416 \mathrm{E}-10$ & -125097.6 & 222773.04 \\
\hline & & EY & $2.773 \mathrm{E}-11$ & -12837.03 & $-4.709 \mathrm{E}-11$ & 222024.993 & $1.799 \mathrm{E}-09$ & -353018.5 \\
\hline
\end{tabular}

Farklı yerel zemin koşulları için yapısal analizler sonucu elde edilen periyod değerleri ve ivme değerlerinin karşılaştırılması Tablo 14'de yapılmıştır. 
Tablo 14. Periyot ve ivme değerlerinin karşılaştırılması

\begin{tabular}{|c|c|c|c|c|c|c|}
\hline $\begin{array}{c}\text { Yerleşim } \\
\text { Birimi }\end{array}$ & $\begin{array}{l}\text { Zemin } \\
\text { sınıfi }\end{array}$ & $\begin{array}{l}\text { Periyot } \\
\text { (s) }\end{array}$ & $\begin{array}{c}\text { Sönüm } \\
\text { Oranı }\end{array}$ & $\begin{array}{c}\mathbf{U x} \text { Acc } \\
\left(\mathbf{m} / \mathbf{s}^{2}\right)\end{array}$ & $\begin{array}{c}\text { Uy Acc } \\
\left(\mathbf{m} / \mathbf{s}^{2}\right)\end{array}$ & $\begin{array}{c}\text { Ux Amp } \\
\text { (m) }\end{array}$ \\
\hline \multirow{5}{*}{ 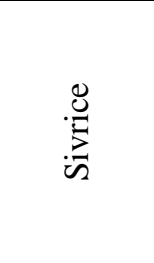 } & $\mathrm{ZA}$ & 1.94659 & 0.05 & 0.21163 & 0.33859 & 17.437015 \\
\hline & $\mathrm{ZB}$ & 1.94659 & 0.05 & 0.21163 & 0.63485 & 17.437015 \\
\hline & $\mathrm{ZC}$ & 1.94659 & 0.05 & 0.3968 & 0.63485 & 32.694403 \\
\hline & $\mathrm{ZD}$ & 1.94659 & 0.05 & 0.49759 & 0.79611 & 40.998782 \\
\hline & $\mathrm{ZE}$ & 1.94659 & 0.05 & 0.62483 & 0.99968 & 51.482787 \\
\hline \multirow{5}{*}{ 兽 } & $\mathrm{ZA}$ & 1.94659 & 0.05 & 0.20506 & 0.32808 & 16.89601 \\
\hline & $\mathrm{ZB}$ & 1.94659 & 0.05 & 0.20506 & 0.61516 & 16.89601 \\
\hline & $\mathrm{ZC}$ & 1.94659 & 0.05 & 0.38449 & 0.61516 & 31.680018 \\
\hline & ZD & 1.94659 & 0.05 & 0.48548 & 0.77674 & 40.001303 \\
\hline & $\mathrm{ZE}$ & 1.94659 & 0.05 & 0.61211 & 0.97933 & 50.434589 \\
\hline
\end{tabular}

\section{Sonuç ve Öneriler}

Zaman içerisinde farklı sebeplerden dolayı depreme dayanıklı yapı tasarım kurallarında değişimler kaçınılmaz olmaktadır. Türkiye'de de son güncellenme 2018 yılında yapıllmıştır. Bu çalışma ile 2018 yılında güncellenen ve 2019 tarihinde yürürlüğe giren Türkiye Deprem Yönetmeliğinde yer alan beş farklı yerel zemin sınıfı için örnek bir çelik yapı için yapısal analizler gerçekleştirilmiştir. Bu yönetmelik ile birlikte sahaya özgü tasarım spektrumlarının kullanılması zorunlu bir hale gelmiştir. Bu çalışmada ayrıca depremsellik açısından riskli olan iki farklı yerleşim birimi için elde edilen tasarım spektrumlarının değişimi de incelenmiştir. Elde edilen sonuçlar çerçevesinde güncellemelerin yapıdeprem ilişkisi açısından önemli kazanımlar içerdiği sonucu ortaya çıkmaktadır.

Her iki yerleşim birimi için seçilen örnek çelik yapının özellikleri değişmediği için doğal titreşim periyodu tüm yerel zemin sınıflarında aynı değeri almıştır. $\mathrm{X}$ ve $\mathrm{Y}$ doğrultularında sadece deprem kuvvetlerinin etkimesi durumunda yerel zemin koşulları zayıfladıkça yer değiştirme değerleri artmıştır. Daha sağlam zeminlerde dönme açısı azalım göstermektedir. PGA değeri daha yüksek olan Sivrice için elde edilen yer değiş̧irme ve dönme değerleri, daha düşük PGA değerine sahip Pütürge için elde edilen yer değiştirme ve dönme değerlerinden aynı zemin sınıfları için daha büyük çıkmıştır. Önceki yönetmelikte aynı deprem bölgesinde yer alan ve aynı tasarım spektrumun kullanılması bu sonuçların aynı çıkmasına neden olacaktı. Bu da sahaya özgü tasarım spektrumlarının gerekliliğini ortaya koymak adına elde edilen önemli sonuçlardan biridir. Bu sonuçlar statik itme analizlerinden elde edilen sonuçlar için geçerliliğini korumuştur. Bir önceki yönetmelik için hesaplanan yer değiştirme ve dönme değerleri her iki yerleşim birimi için eşit, güncel yönetmeliğe göre ise daha düşük değerler almıştır. Bu da yeni deprem yönetmeliğinin yapıların daha sünek davranmasını öngörmesinden kaynaklanmaktadır. Yani güncel yönetmelik yapılara daha fazla hareket etme kabiliyeti sunmaktadır.

Yapıda oluşacak iç kuvvetler, yerel zemin koşulları kötüleştikçe artış göstermiştir. Hem kuvvetler hem de momentler önemli bir ölçüde değişim göstermiştir. Bu da yerel zemin koşullarının önemini bir kez daha gözler önüne sermiştir. Ayrıca yapıda seçilen bir nokta için elde edilen ivme değerleri de yerel zemin koşullarına bağlı olarak artış göstermiştir. Bu durum PGA değerinin yüksek olduğu yerleşim biriminde aynı zemin ve aynı nokta için daha yüksek değerlerin oluşmasına neden olmuştur.

\section{Yazarların Katkısı}

Yazarlar makaleye eşit oranda katkı sağlamıştır.

\section{Çıkar Çatışmasıı Beyanı}

Yazarlar arasında herhangi bir çıkar çatışması bulunmamaktadır. 


\section{Araştırma ve Yayın Etiği Beyanı}

Yapılan çalışmada araştırma ve yayın etiğine uyulmuştur.

\section{Kaynaklar}

[1] Çetin K., Yunatçı A. 2007. Olasılıksal Sismik Tehlike Analizleriyle Tümleştirilmiş, Sahaya Özel Sismik Tepki ve Zemin Sıvılaşması Değerlendirmesi. Altıncı Ulusal Deprem Mühendisliği Konferans1, İstanbul, Türkiye.

[2] Cornell C.A. 1968. Engineering Seismic Risk Analysis. Bulletin of the Seismological Society of America, 58 (5): 1583-1606.

[3] McGuire R.K. 2004. Seismic Hazard And Risk Analysis. Earthquake Engineering Research Institute.

[4] Işık E., Sağır Ç., Tozlu Z., Ustaoğlu Ü.S. 2019. Determination of Urban Earthquake Risk for Kırşehir, Turkey. Earth Sciences Research Journal, 23 (3): 237-247.

[5] Karaşin İ.B., Işık E., Demirci A., Aydın M.C. 2020. Coğrafi Konuma Özel Tasarım Spektrumlarının Betonarme Yapı Performansına Etkisi. Dicle Üniversitesi Mühendislik Fakültesi Mühendislik Dergisi, 11 (3): 1319-1330.

[6] Işık E., Ekinci Y.L., Sayıl N., Büyüksaraç A., Aydın M.C. 2021. Time-dependent Model for Earthquake Occurrence and Effects of Design Spectra on Structural Performance: a Case Study from the North Anatolian Fault Zone, Turkey. Turkish Journal of Earth Sciences, 30 (2): 215234.

[7] Akkar S., Kale Ö., Yakut A., Ceken U. 2018. Ground-Motion Characterization for the Probabilistic Seismic Hazard Assessment in Turkey. Bulletin of Earthquake Engineering, 16 (8): 3439-3463.

[8] Akkar S., Eroğlu Azak T., Çan T., Çeken U., Demircioğlu M.B., Duman T., Zülfikar, Ö. 2014. Türkiye Sismik Tehlike Haritasının Güncellenmesi. AFAD, Proje No: UDAP-Ç-13-06.

[9] Özmen B. 2012. Türkiye Deprem Bölgeleri Haritalarının Tarihsel Gelişimi. Türkiye Jeoloji Bülteni, 55 (1): 43-55.

[10] Çeken U., Dalyan İ., Kılıç N., Köksal T.S., Tekin B.M. 2017. Türkiye Deprem Tehlike Haritaları Interaktif Web Uygulamas1. 4. In Proceedings of the International Earthquake Engineering and Seismology Conference, Bucharest, Romania.

[11] Işık E., Büyüksaraç A., Ekinci Y.L., Aydın M.C., Harirchian E. 2020. The Effect of Site-Specific Design Spectrum on Earthquake-Building Parameters: A Case Study from the Marmara Region (NW Turkey). Applied Sciences, 10 (20): 7247.

[12] Borcherdt R.D., Glassmoyer G. 1992. On the Characteristics of Local Geology and their Influence on Ground Motions Generated by the Loma Prieta Earthquake in the San Francisco Bay Region, California. Bulletin of the Seismological Society of America, 82 (2): 603-641.

[13] Calvi G.M. 2018. Revisiting Design Earthquake Spectra. Earthquake Engineering \& Structural Dynamics, 47 (13): 2627-2643.

[14] Işık E., Kutanis M., Bal İ.E. 2016. Displacement of the Buildings According to Site-specific Earthquake Spectra. Periodica Polytechnica Civil Engineering, 60 (1): 37-43.

[15] Chávez-García F.J., Monsalve Jaramillo H., Gómez Cano M., Vila Ortega J.J., 2018. Vulnerability and Site Effects in Earthquake Disasters in Armenia (Colombia). I-Site Effects. Geosciences, 8 (7): 254.

[16] Strukar K., Sipos T.K., Jelec M., Hadzima-Nyarko M. 2019. Efficient Damage Assessment For Selected Earthquake Records Based on Spectral Matching. Earthquake and Structures 17: 271282.

[17] Kutanis M., Ulutaş H., Işik E. 2018. PSHA of Van Province for Performance Assessment Using Spectrally Matched Strong Ground Motion Records. Journal of Earth System Science, 127 (7):99.

[18] Işık E., Kutanis M. 2015. Determination of Local Site-Specific Spectra Using Probabilistic Seismic Hazard Analysis for Bitlis Province, Turkey. Earth Sciences Research Journal, 19 (2): 129-134. 
[19] Bulut F. 2017. Doğu Anadolu Fayı boyunca Sismik ve A-sismik Tektonik Hareketler: Hazar Gölü Doğu'sunda Sismik Boşluk mu yoksa Krip mi? Afyon Kocatepe Üniversitesi Fen Ve Mühendislik Bilimleri Dergisi, 17 (1): 257-263.

[20] Lei J., Zhao D. 2007. Teleseismic Evidence for a Break-off Subducting Slab under Eastern Turkey. Earth and Planetary Science Letters, 257 (1-2): 14-28.

[21] Nalbant S.S., McCloskey J., Steacy S., Barka A.A. 2002. Stress Accumulation and Increased Seismic Risk in Eastern Turkey. Earth and Planetary Science Letters, 195 (3-4): 291-298.

[22] Utkucu M., Durmuş H., Yalçın H., Budakoğlu E., Işık E. 2013. Coulomb Static Stress Changes before and after the 23 October 2011 Van, Eastern Turkey, Earthquake (M W=7.1): Implications for the Earthquake Hazard Mitigation. Natural Hazards and Earth System Sciences, 13(7):18891902.

[23] Okay A.I., Tüysüz O. 1999.Tethyan Sutures of Northern Turkey. The Mediterranean Basins: Tertiary Extension within the Alpine Orogen. Geol. Soc. Lond. 156: 475-515.

[24] USGS, 2010. Porphyry Copper Assessment of the Tethys Region of Western and Southern Asia; Scientific Investigations Report 2010-5090-V; U.S. Geological Survey: Reston, VA, USA, 2010.

[25] Ekinci Y.L., Ertekin C., Yiğitbaş E. 2013. On the Effectiveness of Directional Derivative Based Filters on Gravity Anomalies for Source Edge Approximation: Synthetic Simulations and a case Study from the Aegean Graben System (Western Anatolia, Turkey). Journal of Geophysics and Engineering, 10(3):035005.

[26] Ekinci Y.L., Yiğitbaş E. 2015. Interpretation of Gravity Anomalies to Delineate Some Structural Features of Biga and Gelibolu Peninsulas, and their Surroundings (North-west Turkey). Geodinamica Acta, 27(4):300-319.

[27] Kalafat D. 1998. Anadolu'nun Tektonik Yapıların Deprem Makanizmaları Açısından İrdelenmesi. Deprem Araștırma Bülteni, 25 (77): 1-217.

[28] Utkucu M., Pınar A., Alptekin Ö. 2003. Uzak Alan P dalga Şekillerinin Sonlu-Fay Ters Çözümünden 22 Mayıs 1971 Bingöl Depremi Kırılma Sürecinin İncelenmesi. Yerbilimleri, 24 (28): 65-79.

[29] Arpat E., Şaroğlu F. 1972. Doğu Anadolu Fayı ile İlgili Bazı Gözlemler ve Düşünceler. MTA Dergisi, 78: 33-39.

[30] Haktanırı T., Elcuman H. 2007. Bingöl İli ve Çevresinde Kaydedilmiş Yıllık Ekstrem Depremlerin İstatistiksel frekans Analizi ve Yörenin Depremselliği. Altıncı Ulusal Deprem Mühendisliği Konferansı, Türkiye.

[31] Aksoy E., Inceoz M., Koçyiğit A. 2007. Lake Hazar Basin: A Negative Flower Structure on the East Anatolian Fault System (EAFS), SE Turkey. Turkish Journal of Earth Sciences, 16 (3): 319338.

[32] Isik E., Aydin M.C., Buyuksarac A. 2020. 24 January 2020 Sivrice (Elazığ) Earthquake Damages and Determination of Earthquake Parameters in the Region. Earthquakes and Structures, 19 (2): 145-156.

[33] AFAD, 2020. https://www.afad.gov.tr/basin-duyurusu---30-elazig-ve-malatyada-mudahale-veiyilestirme-calismalari-suruyor.(Accessed 02 February 2020).

[34] Duman T.Y., Emre Ö. 2013. The East Anatolian Fault: Geometry, Segmentation and Jog Characteristics. In A.H.F. Robertson, O. Parlak, \& U.C. Ünlügenç (Eds.), Geological Development of Anatolia and the Easternmost Mediterranean Region, 372, 495-529. Geological Society, London, Special Publications.

[35] https://deprem.afad.gov.tr/tarihseldepremler. (Accessed 02 February 2020).

[36] http://www.koeri.boun.edu.tr/sismo/2/deprem-bilgileri /tarihsel-depremler/(Accessed 02 February 2020).

[37] Köküm M., Özçelik F. 2020. A Case Study on Reassessment of Historical Earthquakes: 1789 Palu (Elazığ) Earthquake, Eastern Anatolia, Turkey. Maden Tetkik ve Arama Dergisi, 161: 157170.

[38] Sancar T., Akyuz H.S. 2014. Paleoseismology of the Ilipinar Segment (Karliova, Bingol), The North Anatolian Fault Zone. Turkıye Jeoloj1 Bulten1-Geological Bulletın of Turkey, 57(2):35-52.

[39] KOERİ, 2020. http://www.koeri.boun.edu.tr/sismo/2/24-ocak-sivrice-elazig-depremi-2/ (Accessed 02 February 2020).

[40] Türkiye Bina Deprem Yönetmeliği, Afet ve Acil Durum Yönetimi Başkanlığı, Ankara, 2018. 
[41] Türkiye Deprem Tehlike Haritaları İnteraktif Web Uygulaması, https://tdth.afad.gov.tr/ ,2018.

[42] Computer and Structures Inc. 2004: SAP 2000 V14.0.0 (Software), Berkeley, CA.

[43] Çelik Yapıların Tasarım, Hesap ve Yapım Esaslarına Dair Yönetmelik (RG no. 29614), Turkiye Cumhuriyeti Çevre ve Şehircilik Bakanlığı, Ankara, 2016. 